Jurnal Riset Agama

Volume 1, Nomor 3 (Desember 2021): 264-275

DOI: $10.15575 /$ jra.v1i3.15592

https://journal.uinsgd.ac.id/index.php/jra

\title{
Nilai-nilai Sufistik dalam Proses Terapi Pikiran MHT (Mind Healing Technique)
}

\section{Rizki Fadilah}

Jurusan Tasawuf dan Psikoterapi, Fakultas Ushuluddin, UIN Sunan Gunung Djati Bandung rifaaa224@gmail.com

\begin{abstract}
Recently, there has been an interesting phenomenon regarding mind therapy, the Mind Healing Technique, which is an alternative therapy for healing various types of physical and psychological ailments. The purpose of this study is to analyze Sufism values in the Mind Healing Technique process of mind therapy, a case study on student anxiety in facing school exams at SMPN 1 Simpang Teritip Bangka Belitung. This research method uses a qualitative research type, where the data sources come from the results of observations, interviews and other literature related to the research theme. Based on the results of the research that MHT (Mind Healing Technique) mind therapy is not only effective in healing students' anxiety in facing school exams, MHT (Mind Healing Technique) mind therapy also has significant sufistic values. Therefore, researchers highly recommend MHT (Mind Healing Technique) mind therapy as an alternative to physical and psychological healing.
\end{abstract}

Keywords: Mind Healing Technique; Sufistic; Value.

\begin{abstract}
Abstrak
Akhir-akhir ini tampak fenomena menarik mengenai terapi pikiran Mind Healing Technique, yaitu salah satu terapi alternatif penyembuhan berbagai jenis penyakit fisik maupun psikis. Tujuan penelitian ini adalah untuk menganalisis nilai-nilai sufistik dalam proses terapi pikiran Mind Healing Technique studi kasus pada kecemasan siswa dalam menghadapi ujian sekolah di SMPN 1 Simpang Teritip Bangka Belitung. Metode penelitian ini menggunakan jenis penelitian kualitatif, yang mana sumber data berasal dari hasil observasi, wawancara dan literatur lainya yang berkaitan dengan tema penelitian. Berdasarkan hasil penelitian bahwa terapi pikiran MHT (Mind Healing Technique) selain efektif dalam penyembuhan kecemasan siswa dalam menghadapi ujian sekolah, terapi pikiran MHT (Mind Healing Technique) juga memiliki nilai-nilai sufistik yang signifikan.
\end{abstract}


Jurnal Riset Agama, Volume 1, Nomor 3 (Desember 2021): 264-275

Rizki Fadilah/ Nilai-Nilai Sufistik dalam Proses Terapi Pikiran MHT (Mind Healing Technique)

Maka dari itu peneliti sangat merekomendasikan terapi pikiran MHT (Mind Healing Technique) sebagai alternatif penyembuhan secara fisik maupun psikis.

Kata kunci: Mind Healing Technique; Nilai; Sufistik.

\section{Pendahuluan}

Akhir-akhir ini tampak fenomena menarik mengenai terapi MHT Indonesia (Mind Healng Technique-Indonesia) terapi yang cukup baru dan fenomenal beberapa waktu lalu khususnya di UIN Sunan Gunung Djati Bandung jurusan Tasawuf dan Psikoterapi. Terapi yang menggunakan kekuatan pikiran ini, sekarang menjadi salah satu terapi alternatif untuk penyembuhan serta ketenangan jiwa seseorang. Nilai-nilai sufistik pada prosedur penyembuhan ini menjadi salah satu sorotan. Seperti pemaparan asal teori MHT-Center, pada dasarnya Allah merupakan zat yang Maha Segalanya apabila kita sakit, maka Allah-lah yang memberikan semua fasilitas kesembuhan yang dibutuhkan untuk kesembuhan diri seperti self healing mechanism dalam terapi pikiran MHT. Selfhealing mechanism berguna untuk menjaga kesehatan tubuh, memahami bagaimana cara untuk terhindar dari infeksi, radikal bebas, menetralisir racun, memperbaiki kerusakan sel, serta menjaga tubuh agar tetap sehat. Diketahui belakangan ini muncul beberapa media cara pengobatan alternatif, yaitu dengan menggunakan aneka macam tumbuhan (herbal), dan juga ada yang memakai kekuatan zikir (terapi healing), sampai memakai kekuatan batin. Dan salah satu pengobatan yang berkembang saat ini ialah terapi sufistik. Terapi sufistik yang diketahui dengan proses terapi, yaitu menggunakan penyembuhan melalui terapi doa, terapi shalat, terapi pikiran (mind healing), konseling sufistik, dan teknik penyembuhan lainnya yang menggunakan metode-metode sufistik. Pengobatan sufistik adalah pengobatan yang sudah ditujukan oleh para auliya Allah, adapun metodenya yaitu sesuai dengan anjuran Al-Qur'an dan Sunah (Saifullah, 2018). Fenomena yang paling menarik adalah nilai sufistik, dimana MHT merupakan salah satu metode dalam menuntaskan berbagai permasalahan kesehatan. Nilai sufistik demikian digandrungi manusia digital (Syukur, 2012). Khususnya civitas academica atau kalangan masyarakat seperti dosen, mahasiswa serta kalangan pelajar mulai banyak mendatangi pengobatan yang menggunakan metode teknik terapi pikiran, yaitu metode terapi (MHT) Mind Healing Technique dalam penyembuhan penyakit, baik fisik maupun psikis. Alasannya cukup sederhana, pengaplikasian terapi ini tidak membutuhkan tenaga, tetapi penekanan pada pemprograman serta pengendalian pikiran memakai pin atau kode-kode khusus. Melalui kodekode tersebut, cara kerja terapi ini menjadi efektif. Disamping itu, terapi 
Jurnal Riset Agama, Volume 1, Nomor 3 (Desember 2021): 264-275

Rizki Fadilah/ Nilai-Nilai Sufistik dalam Proses Terapi Pikiran MHT (Mind Healing Technique)

MHT juga melibatkan aspek spiritualitas dalam diri manusia. Keyakinan bahwa kesembuhan hanya datang dari Yang Maha Penyembuh adalah kunci utama diangkatnya penyakit dari tubuh. Disisi lain, terapi ini juga menekankan pada proses relaksasi tubuh sehingga pada tahap pascaterapi, klien bisa memperoleh kebugaran serta merasa lebih sehat (Hidayatul Fikra, 2021).

Penelitian mengenai terapi pikiran (MHT) Mind Healing Technique ditinjau dari berbagai prespektif, sudah banyak dilakukan oleh peneliti sebelumnya misalnya, penelitian yang dilakukan oleh Hidayatul Fikra (2021), “Terapi Mind Healing Technique Metode Jarak Jauh Untuk Mengatasi Menstruasi" artikel ini terbit di jurnal Syifa al-Qulub jurnal studi psikoterapi sufistik, dalam penelitian ini penulis menyatakan bahwa terapi Mind Healing Technique berperan terhadap penurunan skala nyeri menstruasi pada berbagai kategori yang dirasakan subjek penelitian serta penurunan skala nyeri tersebut berkisar antara 1-6 angka. Selain dari penurunan skala nyeri pada subjek penelitian dari terapi ini juga berpengaruh terhadap suasana hati yang diakui oleh subjek penelitian bahwa menunjukan mood yang menjadi lebih baik. Beberapa faktor dari keberhasilan selain dari konsentrasi dan kondisi lingkungan yang nyaman, sugesti atau afirmasi yang positif serta aspek spiritualitas seperti zikir juga pemfokusan dalam mekanisme proses terapi untuk mencapai keberhasilan (Hidayatul Fikra, 2021). Selanjutnya penelitian yang dilakukan oleh Ajeng (2020) "Nilai Sufistik Dalam Prosedur Self Healing" juga terbit di jurnal Syifa al-Qulub jurnal studi psikoterapi sufistik, yang melakukan observasinya pada tanggal 11 Februari 2020 pada prosedur self healing dalam pelatihan Mind Healing Technique. Peneliti menyatakan bahwa dari hasil selfhealing melalui Mind Healing Technique ada pengurangan tingkat stress dalam melakukan pengerjaan skripsinya, dari hasil penelitianya juga terdapat nilai-nilai sufistik yang terkandung dalam terapi MHT, yaitu nilai sabar, pasrah, tawakal, konsep takhalli serta tahalli; nilai ridha serta syukur dan nilai taubat yang diungkapkan melalui istighfar (Ajeng Rahmawati, 2020).

O'riordan memberikan pernyataan bahwa dari gambaran penyembuhan merupakan cerminan dari sifat ketuhanan yang dilihat dari bentuk mengasihi, cinta, kasih sayang, kedamaian, serta penghargaan terhadap seseorang. Solihin juga mengungkapkan bahwasanya, objek dari penyembuhan melalui pendekatan sufistik adalah manusia, yaitu yang berhubungan dengan gangguan pada mental stress, kecemasan, gelisah, spiritual, moral ataupun fisik. Selain itu, Solihin juga secara khusus menyatakan bahwa metode para sufi selain betujuan untuk penyucian diri serta evolusi spiritual para sufi yang juga memberikan perawatan, kesembuhan, juga meningkatkan esensi diri dengan penemuan jati diri manusia, citra diri yang suci dan mulia (Ajeng Rahmawati, 2020). 
Jurnal Riset Agama, Volume 1, Nomor 3 (Desember 2021): 264-275

Rizki Fadilah/ Nilai-Nilai Sufistik dalam Proses Terapi Pikiran MHT (Mind Healing Technique)

Haidar Bagir menyatakan bahwa tasawuf atau sufistik ialah ilmu cara mengelola hati serta jiwa agar diri senantiasa selalu mendekatkan diri pada Allah swt, sehingga dapat mencapai derajat makrifat menjadi insan yang kamil. Pada saat ini orang-orang mulai meninggalkan kebiasaan-kebiasaan budaya modern. Kini orang-orang mulai merasakan kebutuhan yang cukup besar teradap spiritualisme sebab kebutuhan terhadap keinginan spiritualisme yang tinggi tersebut, orang-orang terkini mulai mencari-cari berbagai macam cara. Hinduisme dan Buddhisme menjadikan yoga sebagai bagian alternatif manusia modern dalam mencari kepuasan akan dahaga spiritualnya. Namun bagi umat muslim, langkah yang betul untuk umat muslim ialah mengembalikan tasawuf menjadi bagian dalam menjalankan ajaran Syariat Islam pada kehidupan sehari-hari, yaitu dengan cara mengelola hati serta jiwa agar selalu mendekatkan diri pada Allah swt, sehingga dapat mencapai insan yang kamil atau manusia yang unggul serta berakhlak mulia. Manusia wajib menerima pendidikan yang lengkap dari segala aspek. Ketiga unsur pada pendidikan tersebut, yaitu kognitif (intelektual), afektif (emosional) serta praktik wajib terpenuhi, dan tasawuf hadir sebagai ilmu untuk mengontrol hati (emosional), supaya selalu mendekatkan diri kepada Allah swt (Hidayatulloh, 2015).

Maka dari pemaparan diatas, peneliti tertarik untuk menganalisis nilai-nilai sufistik yang terkandung dalam proses terapi pikiran Mind Healing Technique sehingga terbentuklah dua rumusan penelitian. Pertama, apa saja nilai-nilai sufistik dalam proses terapi pikiran (MHT) Mind Healing Technique? Kedua, bagaimana prosedur terapi (MHT) Mind Healing Technique pada kecemasan siswa/i menghadapi ujian sekolah?

Dari rumusan penelitian tersebut, penelitian ini selain untuk mengetahui nilai-nilai sufistik yang terkandung dalam terapi pikiran sufistik. Penelitian ini juga bertujuan untuk menambah inovasi psikoterapi prespektif tasawuf dan menambah khazanah keilmuan tasawuf dan psikoterapi.

\section{Metode Penelitian}

Penelitian ini menggunakan jenis penelitian kualitatif, yang berfokus pada data-data bersifat deksriptif dan analisis data dalam metode terapi yang dikaji. Data-data deskriptif tersebut ialah berupa kajian pembahasan materi yang ada dalam proses metode terapi pikiran (MHT) Mind Healing Technique. Sumber data primer diperoleh dari hasil observasi praktik dan wawancara terhadap siswa/i SMPN 1 Simpang Teritip yang mengaku cemas akan menghadapi ujian sekolah. Sedangkan sumber data sekunder diperoleh dari literatur berupa wawancara founder Mind Healing Technique, artikel-artikel jurnal penelitian serta dokumentasi yang berkaitan dengan terapi MHT. 
Jurnal Riset Agama, Volume 1, Nomor 3 (Desember 2021): 264-275

Rizki Fadilah/ Nilai-Nilai Sufistik dalam Proses Terapi Pikiran MHT (Mind Healing Technique)

\section{Hasil dan Pembahasan}

Kata nilai-nilai sufistik adalah kata majemuk yang berasal dari nilainilai dan sufistik. Kata "nilai" didalam Kamus Besar Bahasa Indonesia karya W.J.S Poerwadarminta, "nilai" memiliki arti harga, yaitu taksiran harga, lalu harga sesuatu yaitu yang dapat diukur atau ditukar; lalu angka kepandaian, atau kadar, mutu, banyak sedikitnya isi, serta sifat-sifat/halhal yang bermanfaat bagi kemanusiaan (Amron, 2014). Nilai juga berasal dari bahasa latin, yaitu vale're yang merupakan bermanfaat, berlaku, berdaya, hingga nilai dianggap sebagai sesuatu yang baik, berguna serta terbaik dari keyakinan beberapa orang atau sekelompok orang. Nilai ialah suatu kualitas yang membuat hal tersebut dihargai, diminati, disukai, bermanfaat serta bisa menjadikan orang yang mendalaminya menjadi bermartabat (Firwan, 2017).

Pada pelatihan MHT angkatan ke-13, penelitian yang dilakukan oleh Ajeng Rahmawati Pertiwi, bahwa instruktur mengungkapkan definisi nilai sufistik tertuju pada pengertian secara harfiah istilah kata nilai dan sufistik. Merujuk pada kamus filsafat karya Lorens Bagus, nilai juga berasal dari Bahasa Inggris, yaitu value yang mempunyai arti bermanfaat, berguna, berlaku, dan kuat. Istilah nilai juga mempunyai beberapa pengertian etimologi. Pertama, harkat yaitu kualitas suatu hal yang disukai, atau diinginkan, bermanfaat dan bisa menjadi salah satu kepentingan. Kedua, keistimewaan; sesuatu yang dihargai, dinilai lebih dan kebaikan. Sedangkan istilah sufitik ialah suatu kata yang berasal dari sufi yang diberi imbuhan-tik, yaitu yang merujuk kepada sifat kesufian. Oleh karena itu, instruktur Naan berpendapat bahwa nilai sufistik ialah ajaran-ajaran, nasihat-nasihat ataupun gagasan-gagasan yang bermanfaat yang ada dimasyarakat, yang mempunyai kesamaan dengan petuah-petuah dan perilaku-perilaku yang baik untuk perjalanan kesufian (Ajeng Rahmawati, 2020).

Disamping itu, aspek spiritual terapi MHT yang disisipkan pada terapi ini, yaitu berupa doa memohon kesembuhan pada Yang Maha Penyembuh dengan niat yang tulus. Dan tentunya, akan mempengaruhi hasil terapi. Hal ini secara tegas menyatakan bahwa memberi kesembuhan ialah hak prerogatif Allah semata, sehingga seseorang tak akan sembuh kecuali dengan izin-Nya. Konsep ini mengacu pada ayat Alquran surat Asy-Syu'ara' ayat 80, yang artinya "dan bila saya sakit, Dialah yang menyembuhkan saya". Sedangkan olah nafas bertujuan mengantarkan klien pada ketenangan (Hidayatul Fikra, 2021).

Secara jelas founder MHT-Indonesia Ahmad Jais Al-Sambasy mengatakan bahwa pada dasarnya Allah ialah zat yang Maha Segalanya apabila kita sakit maka Allah-lah yang memberikan semua fasilitas kesembuhan yang dibutuhkan untuk kesembuhan diri seperti self healing mechanism dalam terapi pikiran MHT. Selfhealing mechanism berguna untuk 
Jurnal Riset Agama, Volume 1, Nomor 3 (Desember 2021): 264-275

Rizki Fadilah/ Nilai-Nilai Sufistik dalam Proses Terapi Pikiran MHT (Mind Healing Technique)

menjaga kesehatan tubuh, memahami bagaimana cara untuk terhindar dari infeksi, radikal bebas, menetralisir racun, memperbaiki kerusakan sel dan menjaga tubuh agar tetap sehat. Kemampuan serta efektivitas prosedur penyembuhan diri ini, yaitu sangat dipengaruhi oleh keadaan pikiran yang positif. Prosedur ini sangat mementingkan keadaan yang relaks-tenangdamai (RTD), karena apabila keadaan seseorang atau pikiran seseorang sedang buruk maka prosedur tersebut tidak bisa berkerja dengan maksimal. Seperti sedang dalam pikiran negatif, ada beban, cemas, tertekan, ketakutan, kemarahan, serta psimis, maka prosedur ini akan sulit bekerja. Maka dari itu, untuk mengaktifkan kembali cara tersebut adalah membuatnya jauh lebih kuat dan efektif serta bekerja lebih maksimal, sehingga melalui temuan terbaru, yaitu metode MHT (Mind Healing Technique) atau terknik penyembuhan melalui pikiran menjadi salah satu solusi dalam penyembuah dari segala penyakit fisik maupun psikis serta ketidak normalan yang ada (MHT-Centre, 2018).

Mind Healing Technique of Indonesia (MHT Indonesia) atau teknik terapi pikiran secara umum adalah salah satu teknik atau cara membangkitkan energi pikiran melalui program pikiran yang secara langsung dapat mempengaruhi tubuh, pikiran itu sendiri, dan jiwa. Pola berpikir, berperilaku, tindakan, maupun perbuatan kebiasaan-kebiasaan tersebut dapat diganti atau diprogram ulang dengan kebiasaan-kebiasaan yang baru, yaitu kebiasaan-kebiasaan yang positif. Pokok penting dari MHT ialah kekuatan pikiran, pikiran tidak mengenal jarak misalnya, Makkah-Madinah-Mesir dengan demikian walaupun kita tidak langsung datang ketempat tersebut namun kita dapat membayangkan menvisualisikan tempat-tempat tersebut. Pikiran juga dapat menembus waktu misalnya sekarang, masa depan yang akan datang, maupun masalalu yang sudah lampau. Pikiran dapat mempengaruhi citra diri, mempengaruhi fisik, mempengaruhi kesehatan dan pikiran juga dapat melahirkan sebuah mindset (Al-Sambasy, Wawancara daring, 2020).

Sebelum melakukan langkah-langkah proses terapi, terapi biasanya menerangkan mind programing terlebih dahulu agar proses terapi berjalan dengan lancar mind programing yaitu:

Visualization $\Longrightarrow \quad$ proses membayangkan dalam pikiran tentang kesembuhan/kesehatan

Paradigm Shift $\Longrightarrow$ penggeseran paradigma atau pandangan dalam penyembuhan (sakit digeser kesehat)

Kata-kata Positif $\Longrightarrow$ relaks-Tenang-Damai (RTD), CintaKasih-Sayang (CKS), Sehat-Sehat-Sehat (S3), Sehat-Semangat-SejahteraSelamanya-Semuanya (S5), Nyaman-Senang-Bahagia (NSB)

SelfHealing $\Longrightarrow \quad$ berdoa, berpikir positif, relaks, fokus dengan niat sembuh, pasrah kepada Allah dan berdzikir atau dengar murottal. 
Jurnal Riset Agama, Volume 1, Nomor 3 (Desember 2021): 264-275

Rizki Fadilah/ Nilai-Nilai Sufistik dalam Proses Terapi Pikiran MHT (Mind Healing Technique)

Atau menggunakan bahasa pikiran bawah sadar (unsonsciuos) dengan menggunakan pin-pin bahasa unconscious, yaitu bahasa positif, misalnya CKS, kalimatnya, "sehat-sehat-sehat," menggunakan self talk, pengulangan pin-pin healing, dan melibatkan perasaan positif.

Disamping pelaksanaan terapi dimulai, perlu adanya komunikasi yang baik antara klien dengan terapis supaya mengantarkan klien dalam kondisi yang nyaman relaks dan tenang sebagaimana yang telah disampaikan oleh founder terapi Mind Healing Technique. Ahmad Jais AlSambasy menyatakan bahwa prolog dari terapis sangatlah penting guna untuk mengatarkan klien dengan keadaan yang relaks, tenang, nyaman serta pasrah kepada Allah swt, namun tidak hanya klien saja, akan tetapi terapispun harus dalam keadaan yang relaks, tenang, nyaman dan pasrah kepada Allah swt agar memberikan hasil terapi yang optimal (Hidayatul Fikra, 2021).

Prosedur dalam pelaksanaan terapi Mind Healing Technique terhadap penurunan kecemasan siswa/i dalam menghadapi ujian sekolah di SMPN 1 Simpang Teritip Bangka Belitung adalah sebagai berikut.

Tabel 1. Prosedur Pelaksanaan terapi Mind Healing Technique

\section{No. Langkah-Langkah}

1 Pada saat memulai terapi baca Bismillah

2 Klien mengambil posisi ternyaman (duduk atau berbaring), sambil menutupkan mata.

$3 \quad$ Klien melakukan olah napas (mengatur ritme pernapasan yaitu dengan menarik napas melalui hidung lalu mengeluarkan napas dengan pelan melalui tiupan mulut) $3 \mathrm{kali}$

Serta menyadari apa yang dirasakan

4 Rilaks-Fokus-Pasrah

5 Kemudian berdoa "Ya Allah, Engkau adalah Maha Penyembuh, sembuhkanlah diriku sekarang dengan kesembuhan yang tidak meninggalkan nyeri dan bekas", "Ya Allah, dengan izin-Mu saya sembuh sekarang".

6 Pin Positif

1)RTD

2)Double Pink

3)BEN

4)S3

Lama durasi 10 menit

$7 \quad$ Klien mengatur napas kembali dengan tarik nafas melalui lalu keluarkan napas pelan-pelan melalui mulut 3kali, sambil membuka kedua mata. 
Jurnal Riset Agama, Volume 1, Nomor 3 (Desember 2021): 264-275

Rizki Fadilah/ Nilai-Nilai Sufistik dalam Proses Terapi Pikiran MHT (Mind Healing Technique)

8 Terakhir mengucapkan syukur/hamdalah

Berikut pelaksanaan terapi terhadap penurunan kecemasan siswa/i dalam menghadapi ujian sekolah di SMPN 1 Simpang Teritip Bangka Belitung, prosedur tertulis adalah seperti yang diatas. Adapun pin-pin yang digunakan dalam terapi ini, yaitu RTD+Double Pink+BEN+S3, yang mana dari pin-pin tersebut terdapat makna dan manfaat tersendiri.

Pertama, yaitu pin RTD adalah rileks-tenang-damai pin ini menjadi pintu masuk dalam penerapan pin-pin yang lainya. Dalam pin ini, klien maupun terapis dikondisikan harus dalam keadaan rileks tenang dan damai. Pada tahap ini, yaitu memvisualisasikan sesuatu yang menenangkan dan membuang segala pikiran-pikiran negatif serta penyakit penyakit hati seperti benci, iri, dengki, marah maupun dendam. Selain membuat rileks, tenang, dan damai. Manfaat relaksasi energi ialah menjadikan tubuh lebih refresh atau segar serta wajah lebih cerah; meningkatkan kreatifitas dan kualitas istirahat seseorang, sehingga menjadikan detak jantung lebih santai atau normal; membuat peredaran darah lebih baik dan lancar serta dapat mengeluarkan zat-zat sisa di dalam tubuh; menjaga kesehatan jantung serta tubuh akan menjadi lebih tenang dan bisa mengontrol hormon stress. Seseorang akan menjadi lebih terkendali dan kesehatan mental akan terjaga dengan lebih baik, dapat merilekskan otot-otot yang tegang setelah aktivitas padat yang melelahkan, dapat melancarkan peredaran darah dan mencegah kram otot saat olahraga, serta dapat menurunkan tekanan darah yang tinggi. Manfaat secara mental dapat membuat suasana hati menjadi lebih bahagia dan dapat mengendalikan amarah (Al-Sambasy, Wawancara Daring, 2021).

Pin Double Pink berguna untuk terapi masalah dan gangguan kejiwaan, kecemasan dan lainya. Cocok seperti yang dialami oleh para siswa/i yang merasakan kecemasan akan menghadapi ujian sekolah karena terapi ini berguna untuk membuat setiap pikiran, aktivitas, dan interaksi sosial menjadi lebih baik dan lebih harmonis. Disamping itu, sangat efektif juga digunakan untuk klien yang depresi, stress, galau, putus asa, keluarga broken home, sulit menemukan jodoh, orang yang dikuatirkan kejahatannya, dan sebagainya. Cinta Kasih Sayang ilmuwan USA, Professor David Hawkins, merilis hasil risetnya : sel-sel kanker paling takut dengan rasa cinta kasih. Menurut David Hawkins sebagian besar orang sakit ialah orang yang selalu menggunakan pikiran yang negatif. Diketahui orang yang sakit ialah orang yang hatinya kurang kasih sayang yang tulus, yang getaran magnetnya dibawah 200 hertz, dan dapat membuat siapapun mudah terserang oleh penyakit. Sedangkan pada seseorang yang memiliki aura yang positif, jika orang tersebut ada disuatu tempat maka ia dapat menggerakan orang atau siapapun serta membuat kondisi menjadi nyaman, rileks dan damai. Perbuatan yang baik, perasaan yang lembut, 
Jurnal Riset Agama, Volume 1, Nomor 3 (Desember 2021): 264-275

Rizki Fadilah/ Nilai-Nilai Sufistik dalam Proses Terapi Pikiran MHT (Mind Healing Technique)

penuh dengan kasih dan sayang, mudah memaafkan, suka beramal, sedekah, lemah lembut dan santun, terbukti frekuensi magnetiknya, yaitu kisaran 400-500 hertz. Sebaliknya benci, marah, emosional, egois, iri, dengki dendam, menyalahkan orang lain, menuntut orang lain, dan tidak pernah memikirkan perasaan orang lain. Hal ini dapat menyebabkan timbulnya penyakit seperti sakit kanker, sakit jantung dan penyakit kronis lainya (AlSambasy, Wawancara Daring, 2021).

Langkah ketiga pin BEN, manfaat BEN adalah mengatasi gangguan dari energi negatif, mengatasi gejolak nafsu liar, selektif dalam mengenal diri, mengatasi halusinasi, was-was dan agar ego, amarah, nafsu tertata dengan baik, serta selalu terhubung dengan cahaya Allah. Pembersihan energi negatif terdapat 7 lapisan kesadaran jiwa manusia, yaitu cara mengenal diri sejati dan diri palsu, yang disingkat menjadi SMBTEAK (jiwa suci, jiwa murni, jiwa bijak, jiwa tenang, jiwa ego, jiwa amarah, jiwa keinginan).

Jiwa suci ialah sebuah tempat dimana bertemunya seorang hamba dengan sang ilahi. Sebuah pertemuan dalam lapisan kesucian hati, pusat bertemunya sang ilahi yang tidak melibatkan unsur duniawi atau tuntutan keinginan yang bersifat duniawi. Jiwa murni atau nafs al-safiyah merupakan jiwa yang tulus dan murni. Jiwa yang murni ialah tingkat kesadaran seseorang yang dapat disebut sebagai insan yang kamil atau bisa dikatakan sebagai manusia yang sempurna atau unggul, memiliki jiwa yang takwa, selalu pasrah serta mendapatkan petunjuk dari Allah swt, yang dijiwanya selalu taat dijalan Allah dan perilakunya tidak keluar dari jalan yang Allah tentukan. Jiwa bijak atau kebijaksanaan ialah suatu kepemahaman atau keputusan terhadap sesuatu yang diiringi dengan nilai-nilai yang selalu optimal yang bertindak dengan kecerdasan, kepemahaman, kearifan maupun wawasan. Jiwa tenang, ialah jiwa yang merasakan akan hadirnya Tuhan disaat apapun yang dialami yang dapat dirasakan kapanpun dan dimanapun berada. Kesadaran jiwa yang tenang sama seperti sesuatu yang terlihat mengendap didalam air, namun yang nampak ialah air yang bersih dan jernih. Apabila diibaratkan dengan fisik manusia, jiwa yang tenang ialah tubuh serta pikiranya yang tetap tenang segar dan jernih. Jiwa ego, ego dapat dikatakan sebagai nafsu, ego merupakan salah satu jiwa yang tidak dapat dihilangkan atau dibuang, akan tetapi ego dapat dikendalikan. Hal inilah yang begitu harus diperhatikan bahwa hal yang terbesar yang harus disadari oleh manusia ialah dapat mengendalikan ego dengan sebaik-baik mungkin serta penuh kehati-hatian. Jiwa amarah, amarah adalah ekspresi dari emosi yang tidak menyenangkan, disulut oleh respon emosional terhadap situasi yang berkembang didalam maupun diluar diri seseorang. Kemarahan sebenarnya bisa menjadi ungkapan kasih sayang, misalnya dengan membela seseorang yang tertindas sehingga amarah dan belas kasih beriringan. Jiwa keinginan, keinginan ialah jiwa yang sangat 
Jurnal Riset Agama, Volume 1, Nomor 3 (Desember 2021): 264-275

Rizki Fadilah/ Nilai-Nilai Sufistik dalam Proses Terapi Pikiran MHT (Mind Healing Technique)

berpengaruh besar terhadap diri manusia karena jiwa keinginan ialah yang akan membawa manusia kejalan yang benar atau yang salah, jiwa keinginan sangat menentukan yaitu apabila seseorang dapat mengatur jiwa keinginan dengan baik maka dapat membawanya kepada rahmatan lillalamin, yang mendekatkan seseorang kepada Allah swt, segala apapun yang diinginkan hanyalah karena Allah swt (Al-Sambasy, Wawancara Daring, 2021).

Langkah keempat, yaitu sehat-sehat-sehat. Menurut Ahmad Jais Alsambasy, sehat yang dimaksud berupa sugesti positif sehingga penyakit tersebut diangkat dan tidak meninggalkan bekas. Pin terakhir yang digunakan adalah $\mathrm{N}$ yaitu nyaman. Pin ini bertujuan agar setelah klien menjalani proses terapi, klien tidak merasakan gangguan atau sesuatu yang mengganjal dalam dirinya sehingga menimbulkan kenyamanan dan ketentraman. Proses terapi ditutup dengan mengucap syukur kepada Allah karena sedikit apapun perubahan yang dialami sebagai hasil terapi ini tidak lepas dari kuasa-Nya (Hidayatul Fikra, 2021).

Nilai sufistik dalam proses terapi Mind Healing Technique juga berbekal dari hasil pra penelitian yang dilakukan pada pelatihan Workshop MHT di Shakti Hotel Februari 2020 dengan pandangan awal berpendapat bahwa dalam proses terapi Mind Healing Technique terkandung nilai-nilai sufistik, minimal dengan pasrah dan yakin atas segala sesuatu yang merupakan semata-mata kehendak Allah swt. Maka dari itu, peneliti ingin mengkaji secara rinci jika ada nilai-nilai sufistik yang terkandung dalam proses terapi Mind Healing Technique.

Ternyata hasil observasi lapangan terhadap kecemasan siswa/i dalam menghadapi ujian sekolah di SMPN 1 Simpang Teritip Bangka Belitung, terasa bernuasa nilai sufistik, berdasarkan hasil wawancara setelah melakukan terapi para siswa/i mengaku suasana pada saat terapi adalah tenang dan damai sehingga pada saat setelah berakhirnya terapi yang awalnya terasa cemas keadaan siswa/i berubah menjadi lebih plong, tenang dan nyaman.

Pernyataan tersebut dibenarkan oleh founder Mind Healing Technique, Ahmad Jais Al-Sambasy mengatakan bahwa nilai-nilai sufistik terkandung dalam terapi Mind Healing Technique, yaitu pada saat memulai terapi membaca bismillah, berniat atas nama Tuhan/Allah, berdoa, pasrah diri kepada Allah, dan diakhiri dengan syukur, yaitu alhamdulillah. Dan dalam praktik terdapat pada terapi pin BEN, ada 7 lapisan jiwa. Peserta dapat mengenali diri sejati dan diri palsu. Diri yang sejati ialah jiwa suci, jiwa murni, jiwa bijak, jiwa tenang, sedangkan diri yang palsu ialah jiwa ego, jiwa amarah dan jiwa keinginan (Ahmad Jais, 2021). 
Jurnal Riset Agama, Volume 1, Nomor 3 (Desember 2021): 264-275

Rizki Fadilah/ Nilai-Nilai Sufistik dalam Proses Terapi Pikiran MHT (Mind Healing Technique)

\section{Kesimpulan}

Hasil penelitian dari observasi lapangan terapi pikiran MHT (Mind Healing Technique) terhadap kecemasan siswa/i dalam menghadapi ujian sekolah di SMPN 1 Simpang Teritip Bangka Belitung, terasa bernuasa nilai sufistik, berdasarkan hasil wawancara setelah melakukan terapi para siswa/i mengaku suasana pada saat terapi adalah tenang dan damai ketika para siswa/i pasrahkan diri kepada Tuhan/Allah sehingga pada saat setelah berakhirnya terapi yang awalnya terasa cemas, keadaan siswa/i berubah menjadi lebih plong, tenang dan nyaman. Secara jelas founder MHT bapak Ahmad Jais Al-Sambasy memaparkan bahwa nilai-nilai sufistik dalam proses terapi MHT ialah pertama, pada saat mulai melakukan terapi, yaitu baca bismillah, lalu berniat kepada Allah swt, berdoa, pasrahkan diri kepada Allah, dan diakhiri dengan kalimat syukur, yaitu hamdulillah. Pada praktik terapi ada 7 lapisan jiwa para siswa/i dapat mengenali diri yang sejati dan diri palsu. Diri yang sejati adalah jiwa suci, jiwa murni, jiwa bijak, jiwa tenang, sedangkan jiwa yang palsu jiwa ego, jiwa amarah dan jiwa keinginan. Berdasarkan hasil penelitian bahwa terapi pikiran MHT (Mind Healing Technique) selain efektif dalam penyembuhan kecemasan terhadap seseorang, terapi pikiran MHT (Mind Healing Technique) juga memiliki nilai-nilai sufistik yang signifikan. Maka dari itu, peneliti sangat merekomendasikan terapi pikiran MHT (Mind Healing Technique) sebagai alternatif penyembuhan secara fisik maupun psikis.

\section{Daftar Pustaka}

Afifah, S. (2019). Self healing melalui mind healing technique untuk mengatasi setress: Penelitian deskriptif pada Mahasiswa jurusa Tasawuf dan Psikoterapi fakultas ushuluddin Islam Negeri Sunan gunung djati Bandung (Doctoral dissertation, UIN Sunan Gunung Djati bandung).

Al-Sambasy, A. J. (2020, Desember). Wawancara daring. (R. Fadilah, Interviewer)

Al-Sambasy, A. J. (2021, Juli). Wawancara Daring. (R. Fadilah, Interviewer) Al-Sambasy, A. J. (2021, Maret). Wawancara Daring. (R. Fadilah, Interviewer)

Amron, S. (2014). Nilai-Nilai sufistik dalam kepemimpinan (studi tentang pemikiran Imam Khomeini) (Doctoral dissertation, UIN Walisongo).

Fikra, H., Gojali, M., \& Naan, N. (2021). Terapi Mind Healing Technique Metode Jarak Jauh untuk Mengatasi Nyeri Menstruasi. Syifa alQulub, 6(1), 42-62.

Firwan, M. (2017). Nilai Moral Dalam Novel Sang Pencerah Karya Akmal Nasrey Basral. Jurnal Bahasa dan Sastra, 2(2), 49-60.

Hidayatulloh, M. R., Kosasih, A., \& Fahrudin, F. (2015). Konsep tasawuf 
Jurnal Riset Agama, Volume 1, Nomor 3 (Desember 2021): 264-275

Rizki Fadilah/ Nilai-Nilai Sufistik dalam Proses Terapi Pikiran MHT (Mind Healing Technique)

Syaikh Nawawi Al-Bantani dan implikasinya terhadap Pendidikan Agama Islam di persekolahan. Tarbawy: Indonesian Journal of Islamic Education, 2(1), 1-15.

MHT-Centre. (2018, Mei). MHT Indonesia. Retrieved from mhtindonesia.wordpress.com.

Rahmawati, A. P., Setiawan, C., \& Naan, N. (2020). Nilai Sufistik Dalam Prosedur Self Healing. Syifa al-Qulub, 5(1), 17-28.

Saifullah, S., Hasbullah, H., \& Hasbi, M. R. (2018). Terapi Sufistik dalam Pengobatan di Pekanbaru Riau. Al-Ulum, 18(2), 341-364.

Syukur, M. A. (2012). Sufi healing: Terapi dalam literatur tasawuf. Walisongo: Jurnal Penelitian Sosial Keagamaan, 20(2), 391412. 